\title{
SYNTHESIS AND EFFICIENT PHOTOCATALYTIC ACTIVITY OF Ag-NANOPARTICLES-DECORATED MESOPOROUS $\mathrm{TiO}_{2}$ SPHERES
}

\author{
SINTEZA IN UČINKOVITA FOTOKATALITIČNA AKTIVNOST \\ MEZOPOROZNIH TiO2 KROGLIC, DEKORIRANIH Z Ag \\ NANODELCI
}

\author{
Shu Cui ${ }^{1,2}$, Yanjuan $\mathrm{Li}^{1}$, Haixin Zhao ${ }^{1}$, Nan $\mathrm{Li}^{1}$, Xiaotian $\mathrm{Li},{ }^{1}$ Guodong $\mathrm{Li}^{1,3}$ \\ ${ }^{1}$ Jilin University, College of Material Science and Engineering, Key Laboratory of Automobile Materials of Ministry of Education, 2699 \\ Qianjin Street, Changchun, 130012, China \\ ${ }^{2}$ Tonghua Normal University, School of Physics, Tonghua, 134002, China \\ 3 Jilin University, College of Chemistry, State Key Laboratory of Inorganic Synthesis and Preparative Chemistry, Changchun 130012, China \\ xiaotianli@jlu.edu.cn
}

Prejem rokopisa - received: 2017-12-04; sprejem za objavo - accepted for publication: 2018-01-25

doi: $10.17222 / \mathrm{mit} .2017 .206$

Nano-heterostructures that integrate the advantages of nanomaterials and heterojunctions have attracted wide interest in photocatalysis. Herein, heterostructured $\mathrm{Ag}$-nanoparticles-decorated mesoporous $\mathrm{TiO}_{2}$ spheres $\left(\mathrm{Ag} / \mathrm{m}\right.$ - $\left.\mathrm{TiO} \mathrm{O}_{2}\right)$ photocatalyst has been successfully prepared by a facile method. The results show that numerous Ag nanoparticles with diameters less than $5 \mathrm{~nm}$ dispersed homogenously onto the mesoporous $\mathrm{TiO}_{2}$ spheres and consequently form heterostructures. $\mathrm{N}_{2}$ adsorption-desorption measurements indicate that the resultant products were porous with highly specific surface area. When used to photodegradate methylene blue $(\mathrm{MB})$, the $\mathrm{Ag} / \mathrm{m}-\mathrm{TiO}_{2}$ heteroarchitecture exhibits significantly enhanced photocatalytic performance compared with mesoporous $\mathrm{TiO}_{2}$ spheres $\left(\mathrm{m}-\mathrm{TiO}_{2}\right)$. Furthermore, the photocatalytic mechanism also has been discussed.

Keywords: titanium oxide, heterostructure, photocatalytic performance

Nanoheterostrukture, ki združujejo dobre lastnosti nanomaterialov in heterospojev, so pritegnile pozornost raziskovalcev fotokatalize. $\mathrm{V}$ prispevku avtorji opisujejo enostavno metodo za uspešno pripravo fotokatalizatorja, in sicer $\mathrm{z}$ Ag nanodelci dekoriranih mezoporoznih $\mathrm{TiO}_{2}$ kroglic $\left(\mathrm{Ag} / \mathrm{m}-\mathrm{TiO}_{2}\right)$. Rezultati karakterizacije so pokazali, da so se številni Ag nanodelci s premerom manj kot $5 \mathrm{~nm}$ homogeno razpršili na mezoporozne $\mathrm{TiO}_{2}$ kroglice. Posledično so tako nastale heterostrukture. Adsorpcijsko-desorpcijske $\mathrm{N}_{2}$ meritve nakazujejo, da so bili nastali produkti porozni z zelo specifično površino. Heterostruktura $\mathrm{Ag} / \mathrm{m}-\mathrm{TiO}_{2}$ kaže občutno povečano fotokatalitično učinkovitost $\mathrm{v}$ primerjavi z mezoporoznimi $\mathrm{TiO}_{2} \mathrm{kroglicami}\left(\mathrm{m}-\mathrm{TiO}_{2}\right)$ pri njegovi porabi za fotodegradacijo metilenskega modrila (MB). Nadalje avtorji v članku razpravljajo še o fotokatalitičnih mehanizmih.

Ključne besede: titanov oksid, heterostruktura, fotokatalitična učinkovitost

\section{INTRODUCTION}

$\mathrm{TiO}_{2}$ has been applied in the fields of biocompatibility, sunscreen, inorganic pigment, solar cells, sensors and catalysis due to its high physical and chemical stability, non-toxicity, and strong availability, as well as effectiveness. ${ }^{1-5}$ So far, $\mathrm{TiO}_{2}$ photocatalytic technology has demonstrated that it is a valid treatment of refractory organic wastewater. ${ }^{6-10}$ However, the anatase $\mathrm{TiO}_{2}$ band gap is $3.2 \mathrm{eV}$, its absorption threshold is $387.5 \mathrm{~nm}$, in the ultraviolet region. ${ }^{11}$ Expanding the adsorption range to the visible region $400-800 \mathrm{~nm}$ is an urgent target. The nano-heterostructure has drawn intense considerations in environmental pollution controlling area, because it can overcome the two obstacles of $\mathrm{TiO}_{2}$ photocatalyst: the dissatisfactory quantum efficiency and the negligable utilization of visible light. In the last few years, a number of materials have been combined with $\mathrm{TiO}_{2}$ to form heterostructure to improve the photo-conversion efficiency of $\mathrm{TiO}_{2}$, such as $\mathrm{Ag},{ }^{12} \mathrm{Au},{ }^{13} \mathrm{CdS},{ }^{14} \mathrm{WO}_{3} \cdot{ }^{15}$
The literature has demonstrated that loading of noble metal nanoparticles is an effective stratagy for enhancing the photocatalytic performance. Relative to other noble metals, Ag is attracting enormous research interest due to its low-cost and non-toxicity. As well known, Ag particles can act as electron acceptor centers and separate electron and hole pairs. ${ }^{16}$ Simultaneously, its Fermi level is lower than that of the conduction band of $\mathrm{TiO}_{2}$, which can drastically improve the photocatalytic property of $\mathrm{TiO}_{2}$ and increase the quantum yield for photocatalytic processes. ${ }^{17}$ As we all know, the size of Ag particles has a great effect on the photocatalytic properties. Reducing the particles' diameter to nano-size is an effective proposal to improve their specific surface area, and consequently the benefits for their performances in lots of surface-related applications. Studies have already confirmed that, ${ }^{8,9,18,19}$ loading silver on the solid carrier to form a composite catalyst is a powerful approach to prevent particles from agglomeration, and enhance the photocatalytic activity. 
In previous work we have successful synthesized mesoporous $\mathrm{TiO}_{2}$ spheres and $\mathrm{Ag}_{3} \mathrm{PO}_{4} / \mathrm{TiO}_{2}$ heteroarchitecture, ${ }^{20}$ and the composite catalysts exhibit excellent photocatalytic performance under visible light. Herein, we demonstrate the synthesis of nano-heterostructured $\mathrm{Ag} /$ mesoporous $\mathrm{TiO}_{2}$ spheres $\left(\mathrm{Ag} / \mathrm{m}-\mathrm{TiO}_{2}\right)$ photocatalyst via a facile and effective method. Profiting from the unique structure with large pores and the relative high specific surface area of the mesoporous $\mathrm{TiO}_{2}$ spheres, the resultant products were investigated as photocatalysts in the degradation of methylene blue under both the UV light and UV-visible light.

\section{EXPERIMENTAL PART}

\subsection{Synthesis of mesoporous $\mathrm{TiO}_{2}$ spheres}

The mesoporous $\mathrm{TiO}_{2}$ spheres $\left(\mathrm{m}-\mathrm{TiO}_{2}\right)$ were obtained by combining the sol-gel method with the solvothermal method, as our previous report. ${ }^{20}$

\subsection{Fabrication of $\mathrm{Ag} / \mathrm{m}-\mathrm{TiO}_{2}$ heterostructured photo- catalyst}

First, $70 \mathrm{mg} \mathrm{m}-\mathrm{TiO}_{2}$ spheres were added into $50 \mathrm{~mL}$ $2 \times 10^{-3} \mathrm{M}$ silver-ammonia $\left(\left[\mathrm{Ag}\left(\mathrm{NH}_{3}\right)_{2}\right] \mathrm{NO}_{3}\right)$ aqueous solution with ultrasonics for $30 \mathrm{~min}$ and then the mixture was kept under a mechanical stir for a while at room temperature to make the $\left[\mathrm{Ag}\left(\mathrm{NH}_{3}\right)_{2}\right]^{+}$ions fully absorbed on the $\mathrm{m}-\mathrm{TiO}_{2}$ surfaces via the electrostatic attraction. After that, $15 \mathrm{~mL}$ PVP ethanol solution was added and refluxed at $70{ }^{\circ} \mathrm{C}$ for $3 \mathrm{~h}$. The final products were centrifuged, washed with ethanol and deionized water, and then dried at $60{ }^{\circ} \mathrm{C}$. The products denoted as $\mathrm{Ag}-1 / \mathrm{m}-\mathrm{TiO}_{2}$.

In addition, the same procedures were performed for the synthesis of sample $\mathrm{Ag}-2 / \mathrm{m}-\mathrm{TiO}_{2}$ and $\mathrm{Ag}-3 / \mathrm{m}-\mathrm{TiO}_{2}$, in which the concentrations of $\left[\mathrm{Ag}\left(\mathrm{NH}_{3}\right)_{2}\right] \mathrm{NO}_{3}$ are $2 \times 10^{-2} \mathrm{M}$ and $2 \times 10^{-1} \mathrm{M}$, respectively.

\subsection{Structural characterizations}

X-ray diffractions (XRD) were operated on a D8 Tools X-ray diffractometer using $\mathrm{Cu}-K \alpha$ radiation $(\lambda=$ $0.154056 \mathrm{~nm}$ ). The morphology and microstructure of the as-prepared samples were observed by scanning electron microscope (SEM/EDS, JEOL JSM-6700F) and transmission electron microscope (TEM, JEM 3010 and Tecnai G2 F20). The porosity of the samples was analyzed at $77 \mathrm{~K}$ by nitrogen adsorption-desorption using the Barrett-Joyner-Halenda (BJH) method on a Quantochrome Autosorb 1 sorption analyzer. The Brunauer-Emmett-Teller (BET) measurement was used to evaluate the specific surface area. X-Ray photoelectron spectroscopy (XPS) was performed by a VG ESCALAB LKII instrument with Mg KR-ADES $(\mathrm{h} v=1253.6 \mathrm{eV})$ source at a residual gas pressure of below $10^{-8} \mathrm{~Pa}$. A PerkinElmer spectrometer using $\mathrm{KBr}$ pellets was adopted to record the Fourier transform infrared (FTIR) spectra.
UV-Vis diffuse reflectance spectroscopy (DRUV-VIS) of the resultant products was characterized by a spectrophotometer Bws003 in the range 190-800 nm and used $\mathrm{BaSO}_{4}$ as a reference standard.

\subsection{Photocatalytic property testing of $\mathrm{Ag} / \mathrm{m}-\mathrm{TiO}_{2}$}

A $120 \mathrm{~mL}$ of MB solution with different concentrations of $30 \mathrm{mg} \mathrm{L}^{-1}$ (ultraviolet light) and $10 \mathrm{mg} \mathrm{L}^{-1}$ (visible light) in the presence of a certain amount of solid catalyst $(12 \mathrm{mg}$ for ultraviolet light and $60 \mathrm{mg}$ visible light) was put into the photoreactor with light source and coolant system, in which the internal light source was a $50 \mathrm{~W}$ high-pressure mercury lamp and a $300 \mathrm{~W}$ halogen lamp. In order to make an adsorption-desorption equilibrium, the solution was kept stirring in dark conditions for half an hour. In the test process, aliquots of dispersion with given intervals of illumination were taken out for investigation. UV/Vis spectroscopy (UV-2550PC) was used to monitor the degradation of the MB. In the calculation of the photocatalytic activities, $C$ and $C_{0}$ stand for the real time concentration of $\mathrm{MB}$ and the initial concentration respectively.

\section{RESULTS}

\subsection{Structural features and morphology}

XRD was used to determine the crystallographic structures of the $\mathrm{m}-\mathrm{TiO}_{2}$ and $\mathrm{Ag}-1 / \mathrm{m}-\mathrm{TiO}_{2}$. All diffraction of $\mathrm{m}-\mathrm{TiO}_{2}$ sphere (Figure 1a) peaks at $2 \theta=38.2^{\circ}$, $44.3^{\circ}, 64.4^{\circ}$, and $77.4^{\circ}$ can be readily indexed to anatase $\mathrm{TiO}_{2}$, which is consistent with the data JCPDS 21-1272. From the calculation from the Scherrer equation, the crystallite size of $\mathrm{TiO}_{2}$ particles is $8.2 \pm 1.6 \mathrm{~nm}$. After loading with $\mathrm{Ag}$, no peaks of $\mathrm{Ag}$ are observed (Figure 1b), indicating the Ag is in the nanosize.

Typical SEM images of the $\mathrm{m}-\mathrm{TiO}_{2}$ spheres and $\mathrm{Ag}-1 / \mathrm{m}-\mathrm{TiO}_{2}$ hybrid spheres are represented in Figure 2.

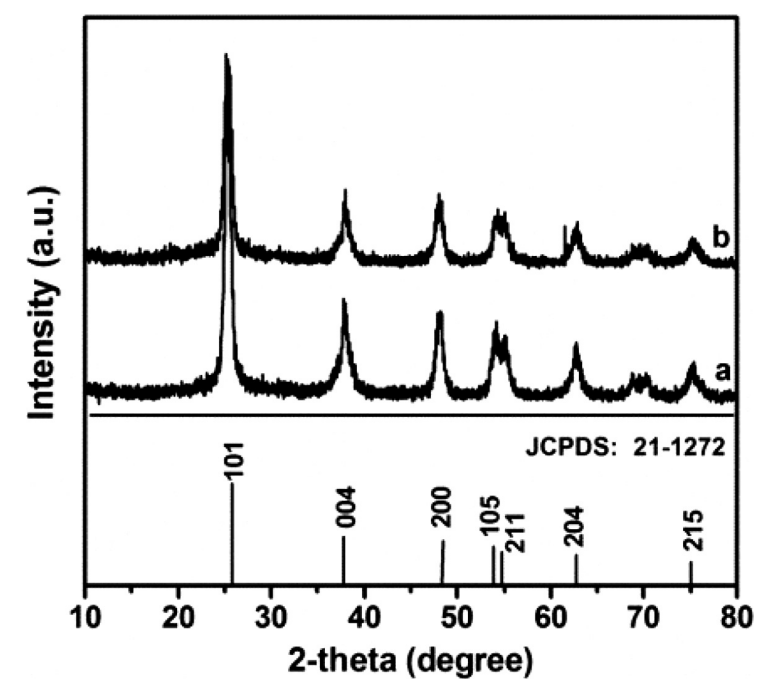

Figure 1: XRD patterns of $\mathrm{m}-\mathrm{TiO}_{2}$ : a) and $\mathrm{Ag}-1 / \mathrm{m}-\mathrm{TiO}_{2}$, b) composites; peaks of JCPDS 21-1272 are shown for comparison 

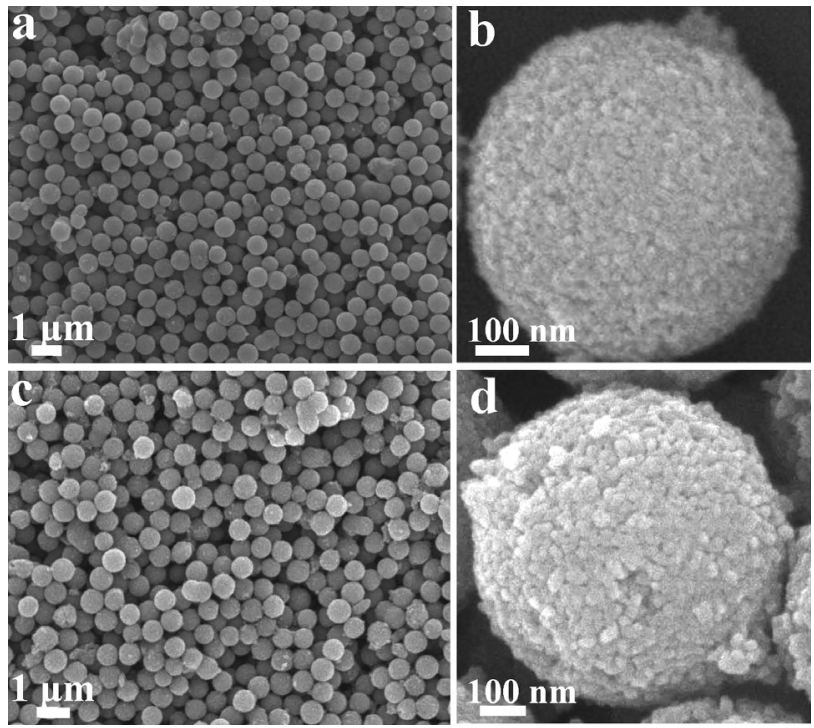

Figure 2: SEM images of: $\mathrm{a}, \mathrm{b}) \mathrm{m}-\mathrm{TiO}_{2}$ and c, d) $\mathrm{Ag}-1 / \mathrm{m}-\mathrm{TiO}_{2}$

The $\mathrm{m}-\mathrm{TiO}_{2}$ spheres composed of numerous nanoparticles have good dispersion with uniform diameter of $\phi 750 \mathrm{~nm}$ (Figures 2a and $\mathbf{2 b}$ ). After loading of Ag nanoparticles (Ag NPs), the diameters and morphologies show no obvious changes (Figures $2 \mathbf{c}$ and $2 \mathbf{2 d}$ ), indicating the Ag particles are very small and well dispersed.

In order to observe clearly, the $\mathrm{Ag}-1 / \mathrm{m}-\mathrm{TiO}_{2}$ was characterized by TEM as shown in Figure 3. Observed from the low magnification of the TEM (Figure 3a), no Ag particles can be found on the surface of the sphere, attributed to the small size and the good distribution of
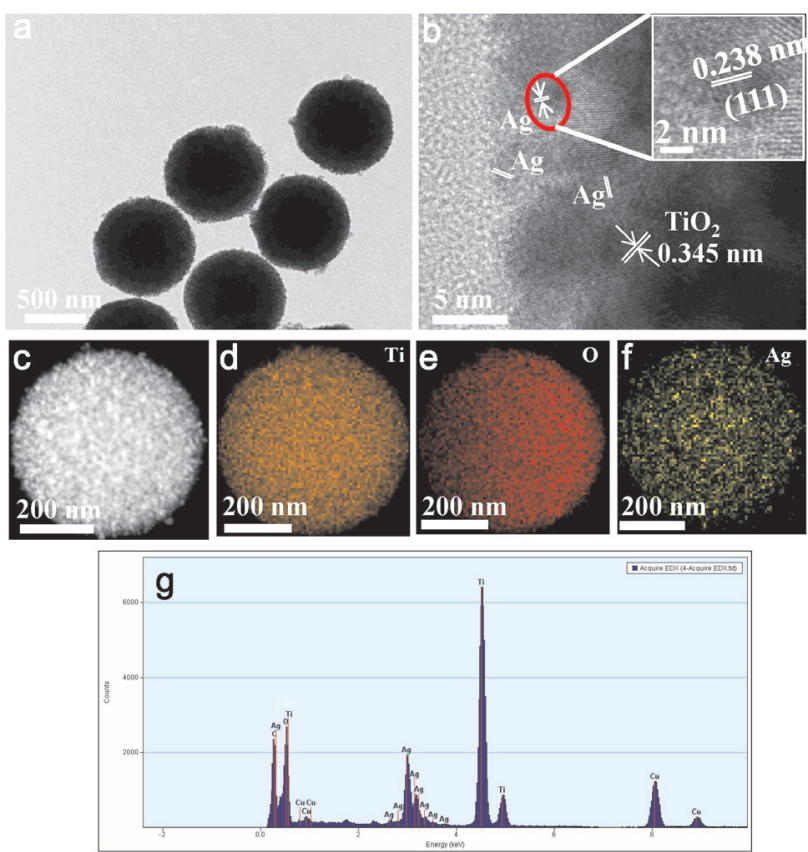

Figure 3: TEM images of $\mathrm{Ag}-1 / \mathrm{m}-\mathrm{TiO}_{2}$ : a) low resolution and b) high resolution, c) TEM mapping images of the $\mathrm{Ag}-1 / \mathrm{m}-\mathrm{TiO}_{2}$ microspheres, d) $\mathrm{Ti}$, e) $\mathrm{O}$, and $\mathrm{f}$ ) Ag element mapping images of the Ag- $1 / \mathrm{m}-\mathrm{TiO}_{2}$ microspheres, g) the corresponding EDS image the Ag particles. Further observations from HRTEM image (Figure 3b) illustrate that there are numerous nanoparticles less than $10 \mathrm{~nm}$ attached on the edge of each $\mathrm{TiO}_{2}$ particle. This result reveals the formation of $\mathrm{Ag}-\mathrm{TiO}_{2}$ heterostructure, where metallic nano-size $\mathrm{Ag}$ and $\mathrm{TiO}_{2}$ layer join. In addition, two sets of lattice fringes of $0.345 \mathrm{~nm}$ and $0.238 \mathrm{~nm}$ are assigned to the $\mathrm{TiO}_{2}$ and Ag respectively (JCPDS card. ${ }^{21}$ 21-1272 and JCPDS card. 04-0783). ${ }^{21}$ To further confirm the presence and distribution of Ag NPs on the $\mathrm{TiO}_{2}$ microspheres, electron mapping analysis was shown in Figures $3 \mathbf{c}$ to 3f. A variety of color distributions displayed as parts of Figures 3d to 3f, confirm the Ti-, O-, and Ag-enriched areas of the sample, respectively, suggesting Ag has been successfully loaded on the surface of $\mathrm{TiO}_{2}$ and dispersed homogenously. The EDS analysis (Figure 3g) of the $\mathrm{Ag}-1 / \mathrm{m}-\mathrm{TiO}_{2}$ microspheres illustrates the existence of $\mathrm{Ti}$, $\mathrm{O}$ and $\mathrm{Ag}$ elements and the percent of $\mathrm{Ag}$ is $5 \%$.

Figure 4 shows nitrogen adsorption properties of $\mathrm{m}-\mathrm{TiO}_{2}$ and $\mathrm{Ag}-1 / \mathrm{m}-\mathrm{TiO}_{2}$. The $\mathrm{m}-\mathrm{TiO}_{2}$ has a type-IV curve with a $\mathrm{H} 1$ hysteresis loop, corresponding to the mesoporous characteristic. ${ }^{22}$ The feature of the curve shows not much change after Ag loading, indicating the mesoporous structure is maintained after incorporating the Ag. However, the BET specific surface areas and pore volumes all reduce with the inclusion of Ag NPs. Before loading of the $\mathrm{Ag}$, the specific surface areas and
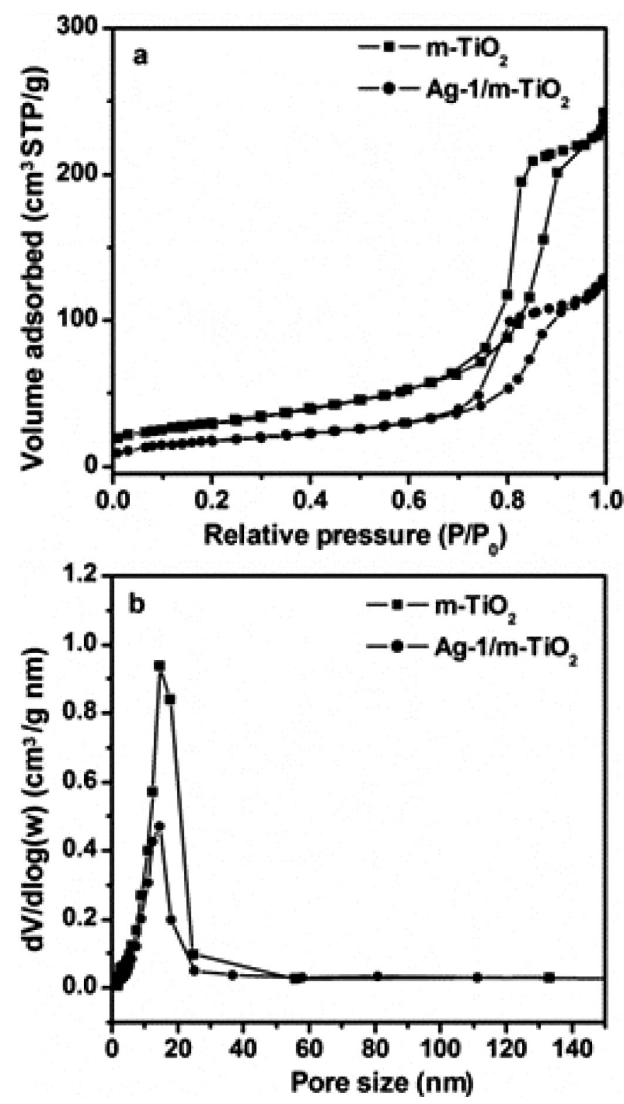

Figure 4: a) Nitrogen adsorption-desorption isotherm and b) the corresponding pore size distribution of $\mathrm{m}-\mathrm{TiO}_{2}$ and $\mathrm{Ag}-1 / \mathrm{m}-\mathrm{TiO}{ }_{2}$ 


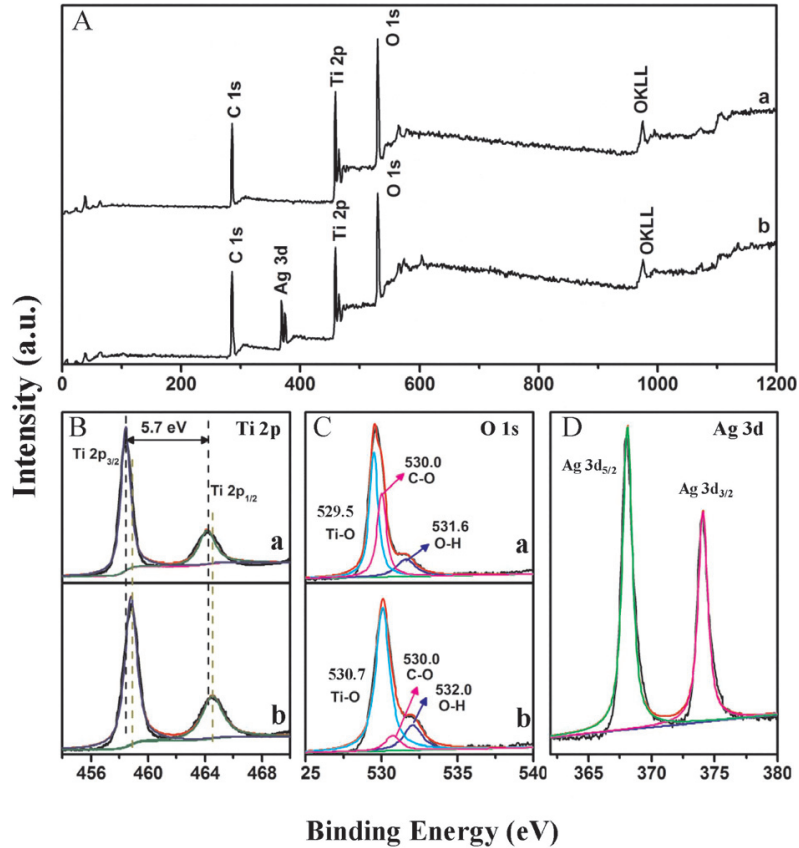

Figure 5: XPS spectra: a) fully scanned spectra, b) Ti 2p, c) O 1s, d) Ag $3 d$

pore volume values of $\mathrm{m}-\mathrm{TiO}_{2}$ are $107.9 \mathrm{~m}^{2} / \mathrm{g}$ and 0.366 $\mathrm{cm}^{3} / \mathrm{g}$. But Ag-1/m- $\mathrm{TiO}_{2}$ has a specific surface area and pore volume of $64.4 \mathrm{~m}^{2} / \mathrm{g}$ and $0.200 \mathrm{~cm}^{3} / \mathrm{g}$. In the pore size distribution curves, samples $\mathrm{m}-\mathrm{TiO}_{2}$ microsphere and $\mathrm{Ag}-1 / \mathrm{m}-\mathrm{TiO}_{2}$ present a similar narrow distribution, which are in the range of $0-22 \mathrm{~nm}$ (Figure $4 \mathbf{b}$ ). The average pore sizes of both samples are $12 \mathrm{~nm}$. A previous report demonstrated that loading metal in the mesostructures would result in the remarkable perturbation in the surface area, ${ }^{23}$ pore volume, and pore size respects. But the same phenomenon was not observed in this case, suggesting the good dispersion and small size of Ag NPs in the $\mathrm{m}-\mathrm{TiO}_{2}$.

XPS has been recognized as a useful measurement for qualitatively determining the surface component and composition for the samples. Figure 5a exhibits the fully scanned spectra from $0 \mathrm{eV}$ to $1200 \mathrm{eV}$, illustrating that the $\mathrm{Ag}-1 / \mathrm{m}-\mathrm{TiO}_{2}$ sample is comprised of $\mathrm{C}, \mathrm{Ti}, \mathrm{O}$ and $\mathrm{Ag}$. Since the $\mathrm{C}$ element is usually ascribed to an adventitious carbon-based contaminant. To harvest further evidences for the a) $\mathrm{m}-\mathrm{TiO}_{2}$ and b) $\mathrm{Ag}-1 / \mathrm{m}-\mathrm{TiO}_{2}$ interaction between the $\mathrm{Ag}$ nanocrystals and $\mathrm{m}-\mathrm{TiO}_{2}$ support, the high-resolution XPS spectra of Ti 2p, O1s and Ag 3d are shown in the Figures $\mathbf{5 b}$ to $\mathbf{5 d}$. Figure $\mathbf{5 b}$ is the high-resolution spectrum of Ti 2 p, two typical peaks lie in $458.8 \mathrm{eV}$ and $464.5 \mathrm{eV}$ are pointed to the oxidation state of $\mathrm{Ti}^{4+}$ in anatase $\mathrm{TiO}_{2}$. As Figure 5c shows, the $\mathrm{O} 1 \mathrm{~s}$ curve can be fitted into three peaks located at (530.0, 530.7 and 532.1) eV, which corresponds to the lattice oxygen from the $\mathrm{C}-\mathrm{O}$, the $\mathrm{OH}$ species resulting from $\mathrm{H}_{2} \mathrm{O}$ and $\mathrm{Ti}-\mathrm{O}$ bond in bulk $\mathrm{TiO}_{2},{ }^{24}$ respectively. More specially, the peak positions for Ti $2 p$ and $\mathrm{O} 1 \mathrm{~s}$ of the $\mathrm{Ag}-1 / \mathrm{m}-\mathrm{TiO}_{2}$ hybrids shift to higher binding energy

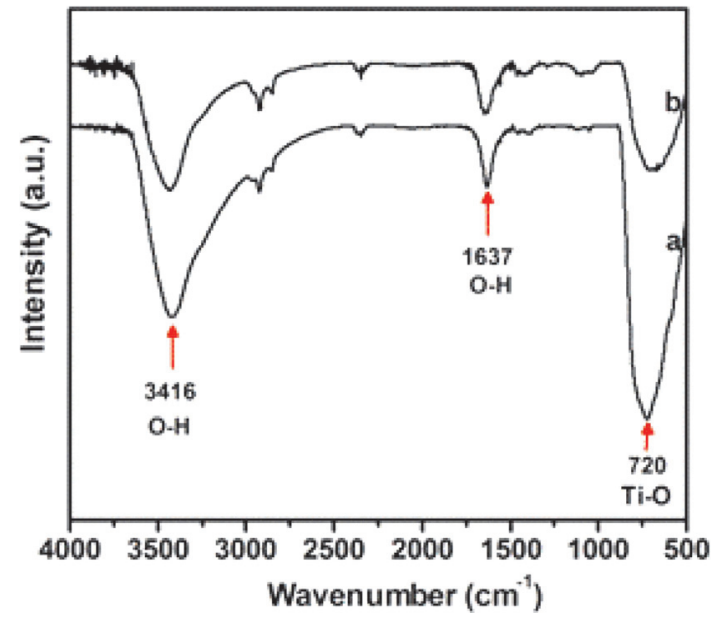

Figure 6: FT-IR spectra of: a) $\mathrm{m}-\mathrm{TiO}_{2}$ and b) $\mathrm{Ag}-1 / \mathrm{m}-\mathrm{TiO}_{2}$
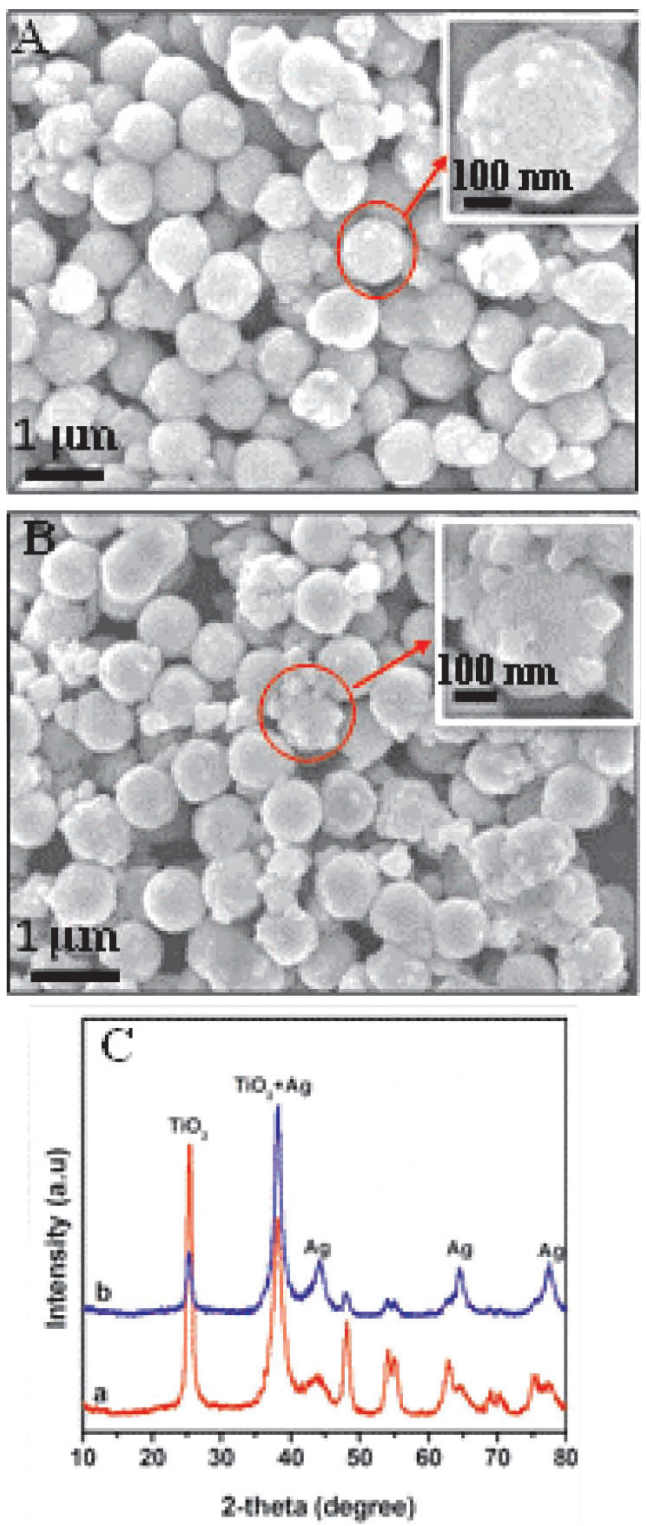

Figure 7: SEM images of: a) Ag-2/m- $\mathrm{TiO}_{2}$, b) $\mathrm{Ag}-3 / \mathrm{m}-\mathrm{TiO}_{2}$, c) XRD spectra of $\mathrm{Ag}-2 / \mathrm{m}-\mathrm{TiO}_{2}$, and $\mathrm{Ag}-3 / \mathrm{m}-\mathrm{TiO}_{2}$ 
bands than those in pure $\mathrm{m}-\mathrm{TiO}_{2}$, which is due to the presence of the oxygen vacancy, resulting in a lower electron density for the $\mathrm{Ti}$ and $\mathrm{O}$ atoms in $\mathrm{Ag}-1 / \mathrm{m}-\mathrm{TiO}_{2}$ hybrids, and it is beneficial for improving the photocatalytic performance. In order to confirm the chemical status of Ag, the corresponding high-resolution XPS spectrum is shown in Figure 5d. There are two individual peaks centered at $368.1 \mathrm{eV}$ and $374.1 \mathrm{eV}$ could be attributed to $\mathrm{Ag} 3 \mathrm{~d} 5 / 2$ and $\mathrm{Ag} 3 \mathrm{~d} 3 / 2$, and the splitting of $3 \mathrm{~d}$ doublet is $6.0 \mathrm{eV}$. This result proves that $\mathrm{Ag}$ is certainly present in the form of metallic $\mathrm{Ag}$ in the hybrids. ${ }^{25}$

The FT-IR spectra of $\mathrm{m}-\mathrm{TiO}_{2}$ and $\mathrm{Ag}-1 / \mathrm{m}-\mathrm{TiO}_{2}$ are displayed in Figure 6. In general, the spectrum of the Ag- $1 / \mathrm{m}-\mathrm{TiO}_{2}$ resembles that of $\mathrm{m}-\mathrm{TiO}_{2}$. The absorption bands located at $3416 \mathrm{~cm}^{-1}$ and $1632 \mathrm{~cm}^{-1}$ in both spectra are assigned to $\mathrm{O}-\mathrm{H}$ group in $\mathrm{H}_{2} \mathrm{O}$. The IR absorptions appear at $720 \mathrm{~cm}^{-1}$ are caused by the Ti-O stretching mode. ${ }^{26}$ Although the spectra of $\mathrm{m}-\mathrm{TiO}_{2}$ and $\mathrm{Ag}-1 / \mathrm{m}$ $\mathrm{TiO}_{2}$ are similar, the intensity of the Ti-O in Ag-1/m$\mathrm{TiO}_{2}$ significantly decreases, indicating that Ag NPs have been successfully loaded in the $\mathrm{m}-\mathrm{TiO}_{2}$.

Furthermore, the effects of the $\left[\mathrm{Ag}\left(\mathrm{NH}_{3}\right)_{2}\right] \mathrm{NO}_{3}$ concentration on the structure of $\mathrm{Ag} / \mathrm{m}-\mathrm{TiO}_{2}$ heterostructures were also investigated, as shown in Figure 7. As shown in Figure 7a, increasing concentration of $\left[\mathrm{Ag}\left(\mathrm{NH}_{3}\right)_{2}\right]^{+}$to $2 \times 10^{-2} \mathrm{M}, \mathrm{m}-\mathrm{TiO}_{2}$ sphere was nearly completely capped by Ag particles and formed a core-shell structure. Further increasing the concentration to $2 \times 10^{-1} \mathrm{M}$, it is obviously observed that large Ag particles with diameter of $50 \mathrm{~nm}$ attach on the $\mathrm{m}-\mathrm{TiO}_{2}$ surface (Figure 7b). The corresponding XRD patterns were shown as Figure 7c. Several well-resolved diffraction peaks appeared at $2 \theta=$ $38.0^{\circ}, 44.2^{\circ}, 64.3^{\circ}$ and $77.2^{\circ}$ are readily indexed to metal $\mathrm{Ag}$ with face-centered cubic structure (JCPDS card no. 04-0783). The intensity of $\mathrm{Ag}$ becomes stronger with the increasing of $\left[\mathrm{Ag}\left(\mathrm{NH}_{3}\right)_{2}\right] \mathrm{NO}_{3}$ concentration, suggesting that the content of $\mathrm{Ag}$ was increased.

\subsection{Photocatalytic performance}

$\mathrm{Ag} / \mathrm{m}-\mathrm{TiO}_{2}$ hybrids as photocatalysts were investigated to degrade methylene blue (MB). The $C / C_{0}$ versus irradiation time is plotted in Figure 8a. In the case of the Ag- $1 / \mathrm{m}-\mathrm{TiO}_{2}$ catalyst, the $\mathrm{MB}$ completely destroyed only takes $25 \mathrm{~min}$. However, with the increasing of $\mathrm{Ag}$, the photocatalytic performance reduces. The reasonable explanation is that Ag particles wrapped on the surface of $\mathrm{m}-\mathrm{TiO}_{2}$ reducing the utilization of mesopores, consequently decreasing the contact area between the MB and the catalyst. In other words, only Ag particles play a catalytic role $\left(\mathrm{Ag}-2 / \mathrm{m}-\mathrm{TiO}_{2}\right)$. Especially, the catalytic activity significantly reduced, even lower than $\mathrm{m}-\mathrm{TiO}_{2}$. This may be due to the large particle size of the $\mathrm{Ag}$ wrapped on $\mathrm{m}-\mathrm{TiO}_{2}$ surface, which reduces the adsorption rate of the light, consequently weakening the photocatalytic performance. Figure $\mathbf{8 b}$ shows UV-vis spectra for the degradation of the $\mathrm{MB}$ catalyzed by $\mathrm{Ag}-1 / \mathrm{m}-\mathrm{TiO}_{2}$
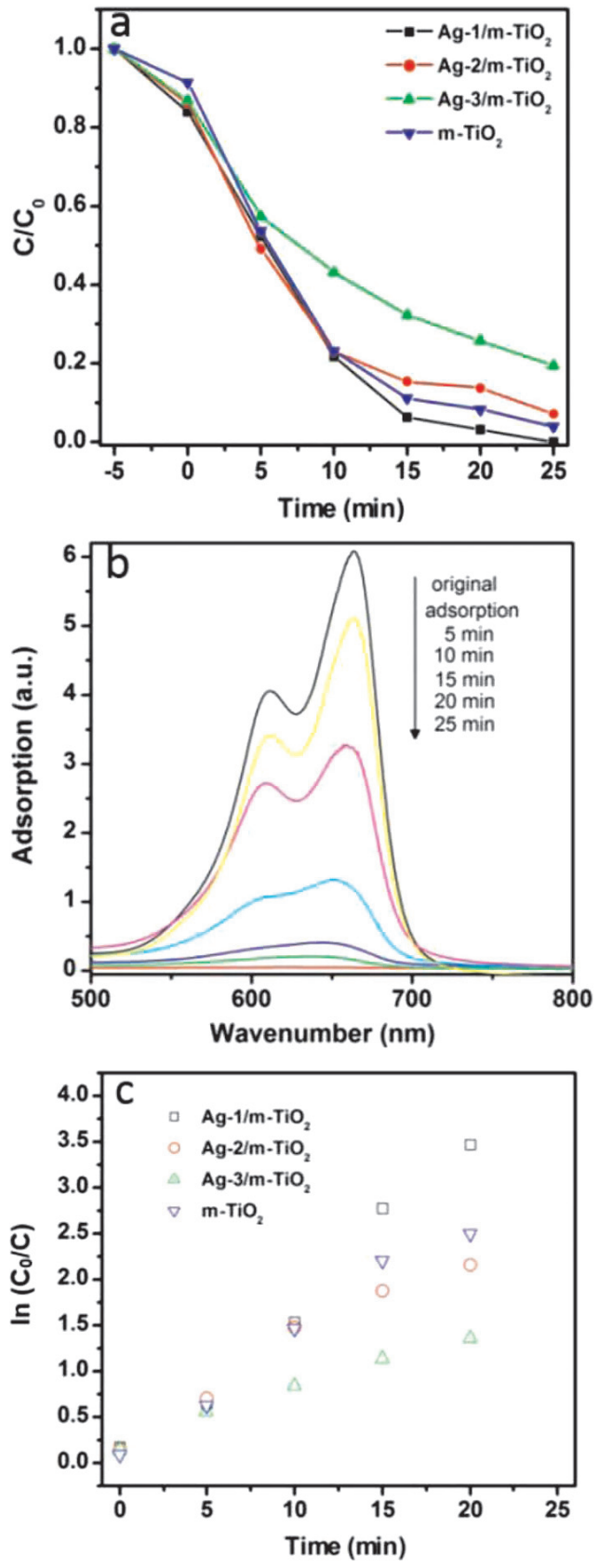

Figure. 8: a) Photocatalytic degradation of MB under UV light of different catalysts, b) time-dependent adsorption spectra of MB with $\left.\mathrm{Ag}-1 / \mathrm{m}-\mathrm{TiO}_{2}, \mathrm{c}\right)$ the corresponding kinetic data for the degradation of MB

under UV light. The typical peak of MB at $665 \mathrm{~nm}$ disappears fast, suggesting that this sample exhibits excellent photocatalytic activity.

The photocatalytic degradation of MB allows for pseudo first-order kinetics, and the apparent degradation rate constant $k$ could be determined by $\ln \left(C_{0} / C\right)=k t$. The relationships between $\ln \left(C_{0} / C\right)$ and the reaction time of all the photocatalysts are linear, as shown in Figure 8c. It can be observed that $\mathrm{Ag}-1 / \mathrm{m}-\mathrm{TiO}_{2}$ possesses the highest apparent reaction rate constant, certifying the high photocatalytic activity, which is attributed 

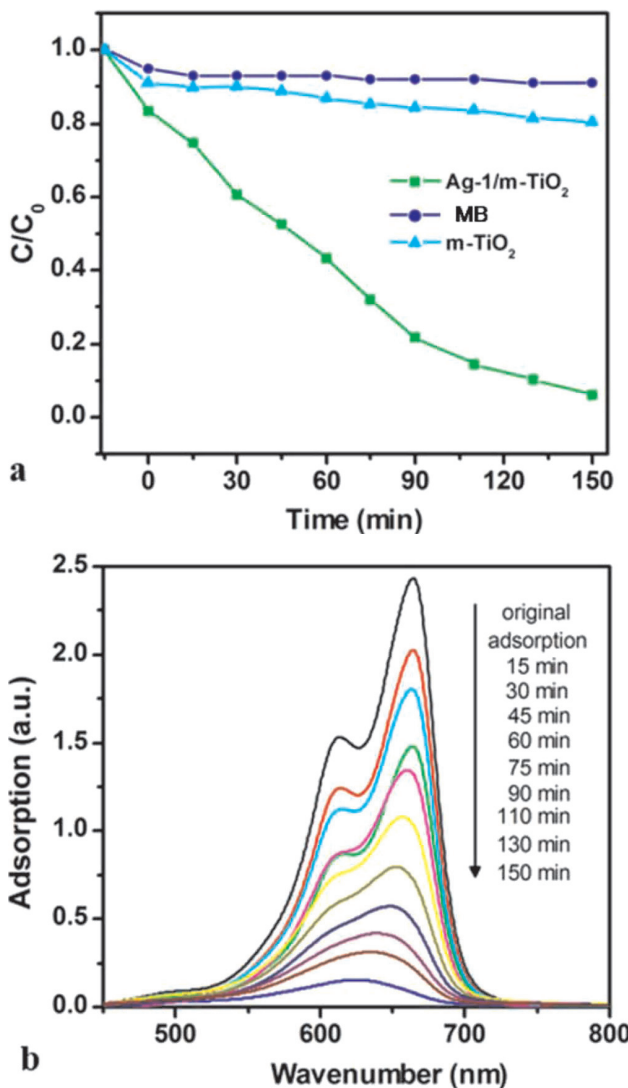

Figure 9: a) Photocatalytic degradation of MB under visible light of different catalysts, b) time-dependent adsorption spectra with $\mathrm{Ag}-1 / \mathrm{m}-\mathrm{TiO}_{2}$

to its unique structure. First, the large mesopores structure and specific surface area can enlarge the contact between the organics and photocatalyst. Secondly, the heterostructure is beneficial for the separation between photo-generated electron and hole.

Combined with the results of SEM (Figure 2) and phtocatalytic activity under UV light (Figure 8), $\mathrm{Ag}-1 / \mathrm{m}-\mathrm{TiO}_{2}$ was chosen as photocatalyst used under visible light irradiation. Figure 9a exhibits the degradation of $\mathrm{MB}$ with times. Compared with $\mathrm{m}-\mathrm{TiO}_{2}$, loading metallic $\mathrm{Ag}$ on the surface of $\mathrm{m}-\mathrm{TiO}_{2}$ spheres increases the photocatalytic performance. After $150 \mathrm{~min}$ of irradiation, $96 \% \mathrm{MB}$ was destroyed. It indicates that the $\mathrm{Ag}-\mathrm{TiO}_{2}$ heterojunction could enhance the electroncharge separation efficiency. Figure $\mathbf{9 b}$ shows the changes of the absorption spectra of the MB aqueous solution exposed to visible light for various times in the presence of $\mathrm{Ag}-1 / \mathrm{m}-\mathrm{TiO}_{2}$. Under visible-light illumination, the MB absorption rate rapid decreases at $665 \mathrm{~nm}$.

\section{DISCUSSION}

UV-vis diffuse reflectance (DRUV-VIS) was used to further investigate the adsorption of products under visible light and UV light. The DRUV-VIS for $\mathrm{Ag} / \mathrm{m}-\mathrm{TiO}_{2}$ and pure $\mathrm{m}-\mathrm{TiO}_{2}$ were compared, as displayed in Figure 10a. The pure $\mathrm{m}-\mathrm{TiO}_{2}$ spheres show the adsorption edges at about $390 \mathrm{~nm}$, which is ascribed to the charge transfer from the valence band (mainly formed by $2 p$ orbitals of the oxide anions) to the conduction band (mainly formed by $3 \mathrm{~d}_{\mathrm{t} 2 \mathrm{~g}}$ orbitals of the $\mathrm{Ti}^{4+}$ cations) and no adsorption can be observed in the visible-light region. ${ }^{27}$ While for $\mathrm{Ag} / \mathrm{m}-\mathrm{TiO}_{2}$, the high absorbance begins from $400 \mathrm{~nm}$ to the whole visible region, which is the typical features of the surface plasmon absorption of spatially restricted electrons from Ag NPs and further confirming the presence of the heterostructure between $\mathrm{Ag}$ and $\mathrm{TiO}_{2}$. The absorbance in the range of visible region for the $\mathrm{Ag}-1 / \mathrm{m}-\mathrm{TiO}_{2}$ system increases and basically stays constant owing to the uniformly distributed Ag NPs on $\mathrm{m}-\mathrm{TiO}_{2}$. While for $\mathrm{Ag}-2 / \mathrm{m}-\mathrm{TiO}_{2}$, the absorption is even higher than that of $\mathrm{Ag}-1 / \mathrm{m}-\mathrm{TiO}_{2}$ at the beginning and then decreases gradually from $550 \mathrm{~nm}$ to $800 \mathrm{~nm}$, suggesting that $\mathrm{Ag}$ NPs on $\mathrm{m}-\mathrm{TiO}_{2}$ are not evenly distributed. ${ }^{28}$ In particular, the absorption of $\mathrm{Ag}-3 / \mathrm{m}-\mathrm{TiO}_{2}$ decreases significantly ascribed to large amount of $\mathrm{Ag}$ particles wrapped on $\mathrm{m}-\mathrm{TiO}_{2}$ resulting in the high energy surface is covered.

Under UV illumination, $\mathrm{TiO}_{2}$ is activated and generates electron-hole pairs. Ag NPs have a favorable Fermi level ( $0.4 \mathrm{~V}$ vs. normal hydrogen electrode NHE), which can serve as a good electron acceptor. ${ }^{17}$ Thus, Ag can trap the photogenerated electron in the conduction band of $\mathrm{m}-\mathrm{TiO}_{2}$ for facilitating quick electron transfer and it is energetically favorable. ${ }^{29}$ Consequently, it lowers the recombination of photo-induced charges, as exhibited in Figure 10b. Furthermore, The Fermi level shifts to more negative and renders $\mathrm{Ag}$ more reductive due to the accumulation of trapped electrons in $\mathrm{Ag}$ nanopaticles. Both the photogenerated electrons in $\mathrm{TiO}_{2}$ as well as the trapped electrons in $\mathrm{Ag}$ will react with $\mathrm{O}_{2}$, and yield some highly oxidative species, for example, peroxide
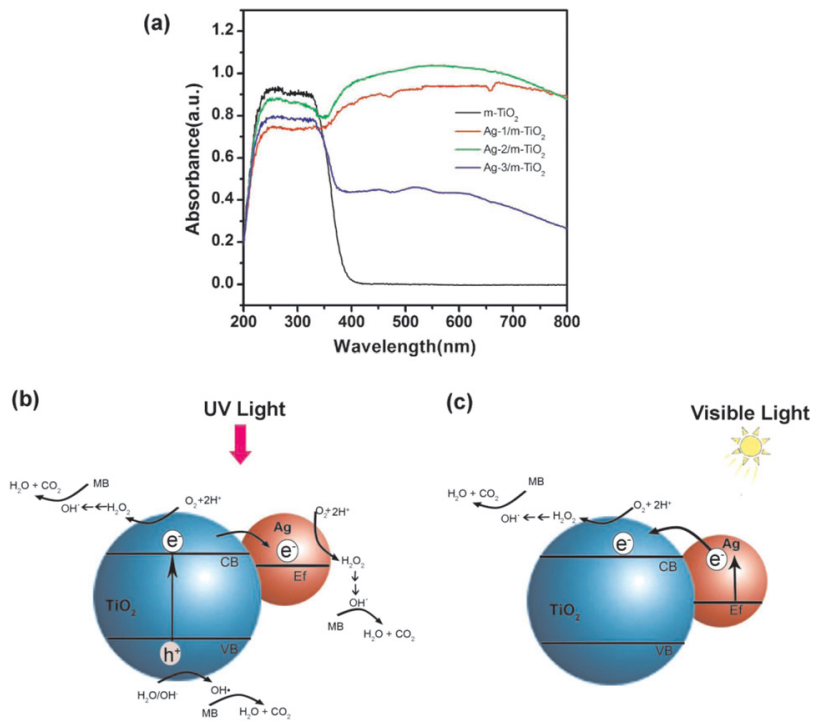

Figure 10: a) UV-vis diffuses reflectance spectra of $\mathrm{Ag} / \mathrm{m}-\mathrm{TiO}_{2}$ composites and schematics of photocatalytic mechanism, b) UV light and c) visible light 
$\left(\mathrm{H}_{2} \mathrm{O}_{2}\right)$, which can further generate hydroxyl radical $(\mathrm{OH} \cdot)$ and effectively degrade organic substrates. Simultaneously, the holes in the valence band of $\mathrm{m}-\mathrm{TiO}_{2}$ can react with $\mathrm{H}_{2} \mathrm{O}$ or $\mathrm{OH}^{-}$and also generate $\mathrm{OH} \cdot$, which then decompose MB. The degradation rate is much faster under UV illumination because both electrons and holes generated from $\mathrm{m}-\mathrm{TiO}_{2}$ can give contributions to the degradation of $\mathrm{MB}$. Ag loaded in $\mathrm{m}-\mathrm{TiO}_{2}$ enlarges the interface area and improves the charge separation and consequently elevates the photocatalytic performance. For $\mathrm{Ag} / \mathrm{m}-\mathrm{TiO}_{2}$ composite samples, Ag can trap the photogenerated electrons in the conduction band of $\mathrm{m}-\mathrm{TiO}_{2}$ and consequently prolongs the lifetime of holes in the valence band. However, the loading of $\mathrm{Ag}$ would also give adverse effects on the photocatalytic performance that $\mathrm{Ag}$ can be excited, generating electrons and then transfer back to $\mathrm{m}-\mathrm{TiO}_{2}$, which prevents the separation of charges in $\mathrm{m}-\mathrm{TiO}_{2}$. Therefore, the amount of $\mathrm{Ag}$ is a key to affect the photocatalytic performance.

Under UV-visible illumination (Figure 10c), MB molecules and nano-size Ag can both be excited by visible light, which results in self-photosensitization and hot electrons transferred to the conduction band of $\mathrm{m}-\mathrm{TiO}_{2}$, respectively. To further investigate the effects of visible light added, an enhancement factor EF, which is defined as $E F=k^{\prime}{ }_{\text {Uv-vis }} / k^{\prime}$ Uv is used as a reference. According to reference no. 8 , the EF values of $\mathrm{m}-\mathrm{TiO}_{2}$ ad $\mathrm{Ag}-1 / \mathrm{m}-\mathrm{TiO}_{2}$ are 1.81 and 1.79 , respectively, which is inversely related to the specific decay rate under visible illumination. It implies the smaller EF, better photocatalytic performance under UV-visible irradiation.

According to the above discussions, it is concluded that the loading Ag composites is indeed improving the photocatalytic performance of $\mathrm{m}-\mathrm{TiO}_{2}$.

\section{CONCLUSIONS}

In summary, $\mathrm{Ag} / \mathrm{m}-\mathrm{TiO}_{2}$ heterostructure photocatalysts have been prepared by a facile method. Ag NPs homogeneously distribute on the $\mathrm{m}-\mathrm{TiO}_{2}$ spheres. The $\left[\mathrm{Ag}\left(\mathrm{NH}_{3}\right)_{2}\right] \mathrm{NO}_{3}$ concentration is critical for controlling the particle size and the distribution of Ag. Moreover, the hybrids with large pores and a high specific surface area determine $\mathrm{Ag} / \mathrm{m}-\mathrm{TiO}_{2}$ as a candidate for the catalyst. The photocatalytic measurement results demonstrate that the Ag- $1 / \mathrm{m}-\mathrm{TiO}_{2}$ manifests its outstanding performance under both UV and visible light, compared with $\mathrm{m}-\mathrm{TiO}_{2}$.

Acknowledgements

This work was supported by the National Natural Science Foundation of China (No. 21076094 and 21673097).

\section{REFERENCES}

${ }^{1}$ A. F. K. Honda, Electrochemical photolysis of water at a semiconductorelectrode, Nature, 238 (1972), 37-38

${ }^{2}$ J. M. Zhang, X. Jin, P. I. Morales-Guzman, X. Yu, H. Liu, H. Zhang,

L. C. Razzari, P. Jerome, Engineering the absorption and field enhancement properties of $\mathrm{Au}-\mathrm{TiO}_{2}$ nanohybrids via whispering gallery mode resonances for photocatalytic water splitting, ACS Nano, 10 (2016), 4496-4503, doi:10.1021/acsnano.6b00263

${ }^{3}$ A. Gomathi, S. R. C. Vivekchand, A. Govindaraj, C. N. R. Rao, Chemically bonded ceramic oxide coatings on carbon nanotubes and inorganic nanowires, Adv. Mater., 17 (2005), 2757-2761

${ }^{4}$ A. Shahat, E. A. Ali, M. E. Shahat, Colorimetric determination of some toxic metal ions in post-mortem biological samples, Sensors and Actuators B: Chemical, 221 (2015), 1027-1034, doi:10.1016/ j.snb.2015.07.032

${ }^{5}$ C. Wang, C. Shao, L. Wang, L. Zhang, X. Li, Y. Liu, Electrospinning preparation, characterization and photocatalytic properties of $\mathrm{Bi}_{2} \mathrm{O}_{3}$ nanofibers, J. Colloid Interf. Sci., 333 (2009), 242-248

${ }^{6}$ X. Li, P. Liu, Y. Mao, M. Xing, J. Zhang, Preparation of homogeneous nitrogen-doped mesoporous $\mathrm{TiO}_{2}$ spheres with enhanced visible-light photocatalysis, Appl. Cataly. B, Environ., 164 (2015), 352-359, doi:10.1016/j.apcatb.2014.09.053

${ }^{7}$ V. Iliev, D. Tomova, A. Eliyas, S. Rakovsky, M. Anachkov, L. Petrov, Enhancement of the activity of $\mathrm{TiO}_{2}$-based photocatalysts: a review, Bulgarian Chem. Commun., 47 (2015), 1-5

${ }^{8}$ Y. Z. He, P. Basnet, S. E. H. Murph, Y. P. Zhao, Ag Nanoparticle Embedded $\mathrm{TiO}_{2}$ Composite Nanorod Arrays Fabricated by Oblique Angle Deposition, Toward Plasmonic Photocatalysis, ACS Appl. Mater. Interf., 5 (2013), 11818-11827

${ }^{9}$ Y. C. Liang, C. C. Wang, C. C. Kei, Y. C. Hsueh, W. H. Cho, T. P. Perng, Photocatalysis of $\mathrm{Ag}$-Loaded $\mathrm{TiO}_{2}$ nanotube arrays formed by atomic layer deposition, J. Phys. Chem. C, 115 (2011), 9498-9502

${ }^{10}$ D. Chen, L. Cao, F. Huang, P. Imperia, Y. B. Cheng, R. A. Caruso, Synthesis of monodisperse mesoporous titania beads with controllable diameter, high surface areas, and variable pore diameters (14-23 nm), J. Am. Chem. Soc., 132 (2010), 4438-4444

${ }^{11}$ O. K. Dalrymple, E. Stefanakos, M. A. Trotz, D. Y. Goswami, A review of the mechanisms and modeling of photocatalytic disinfection, Appl. Cataly. B, Environ., 98 (2010), 27-38

${ }^{12}$ H. F. Shi, Y. C. Yua, Y. Zhanga, X. J. Feng, X. Y. Zhao, H. Q. Tan, S. U. Khana, Y.G. Lia, E. B. Wang, Polyoxometalate/TiO $/ 2$ Ag composite nanofibers with enhanced photocatalytic performance under visible light, Applied Catalysis B, Environmental, 221 (2018), 280-289, doi:10.1016/j.apcatb.2017.09.027

${ }^{13}$ Y. R. Fang, Y. Jiao, K. L. Xiong, R. B. Ogier, Z. J. Yang, S. W. Gao, A. B. Dahlin, M. Käll, Plasmon enhanced internal photoemission in antenna-spacer-mirror based $\mathrm{Au} / \mathrm{TiO}_{2}$ nanostructures, Nano Lett., 15 (2015), 4059-4065, doi:10.1021/acs.nanolett.5b01070

${ }^{14}$ S. Dutta, R. Sahoo, C. Ray, S. Sarkar, J. Jana, Y. Negishi, T. Pal, Biomolecule-mediated $\mathrm{CdS}-\mathrm{TiO}_{2}$-reduced graphene oxide ternary nanocomposites for efficient visible light-driven photocatalysis, Dalton T., 44 (2014), 193-201

${ }^{15}$ B. A. Lu, X. D. Li, T. H. Wang, E. Q. Xie, Z. Xu, $\mathrm{WO}_{3}$ nanoparticles decorated on both sidewalls of highly porous $\mathrm{TiO}_{2}$ nanotubes to improve UV and visible-light photocatalysis, J. Mater. Chem. A, 1 (2013), 3900-3906

${ }^{16}$ Y. Bi, H. Hu, S. Ouyang, Z. Jiao, G. Lu, J. Ye, Selective growth of $\mathrm{Ag}_{3} \mathrm{PO}_{4}$ submicro-cubes on $\mathrm{Ag}$ nanowires to fabricate necklace-like heterostructures for photocatalytic applications, J. Mater. Chem., 22 (2012), 14847-14850

${ }^{17}$ P. V. Kamat, Meeting the Clean Energy Demand, Nanostructure Architectures for Solar Energy Conversion, J. Phys. Chem. C, 111 (2007), 2834-2860

${ }^{18}$ S. Ko, J. Nanosci. Photochemical Synthesis, Characterization and Enhanced Visible Light Induced Photocatalysis of Ag Modified $\mathrm{TiO}_{2}$ Nanocatalyst, Nanotechno., 14 (2014), 6923-6928

${ }^{19}$ P. Shahini, A. A. Ashkarran, Immobilization of plasmonic Ag-Au NPs on the $\mathrm{TiO}_{2}$ nanofibers as an efficient visible-light photocatalyst, Colloids and Surfaces A, 537 (2018), 155-162, doi:10.1016/ j.colsurfa.2017.10.009

${ }^{20}$ Y. J. Li, L. M. Yu, N. Li, W. F. Yan, X. T. Li, Heterostructures of $\mathrm{Ag}_{3} \mathrm{PO}_{4} / \mathrm{TiO}_{2}$ mesoporous spheres with highly efficient visible light 


\section{S. CUI et al.: SYNTHESIS AND EFFICIENT PHOTOCATALYTIC ACTIVITY OF Ag-NANOPARTICLES-DECORATED ...}

photocatalytic activity, J. Colloid Interf. Sci., 450 (2015), 246-253, doi:10.1016/j.jcis.2015.03.016

${ }^{21}$ J. Ma, X. Guo, Y. Zhang, H. Ge, Catalytic performance of $\mathrm{TiO}_{2} @ \mathrm{Ag}$ composites prepared by modified photodeposition method, Chem. Eng. J., 258 (2014), 247-253

${ }^{22}$ J. C. Vartuli, K. D. Schmitt, C.T. Kresge, W. J. Roth, M. E. Leonowicz, S. B. McCullen, S. D. Hellring, J. S. Beck, J. L. Schlenker, Effect of Surfactant/Silica Molar Ratios on the Formation of Mesoporous Molecular Sieves: Inorganic Mimicry of Surfactan Liquid-Crystal Phases and Mechanistic Implications, Chem. Mater., 6 (1994), 2317-2326

${ }^{23}$ Y. Chi, J. C. Tu, M. G. Wang, X. T. Li, Z. K. Zhao, One-pot synthesis of ordered mesoporous silver nanoparticle/carbon composites for catalytic reduction of 4-nitrophenol, J. Colloid Interf. Sci., 423 (2014), 54-59

${ }^{24}$ Y. Xia, F. Li, Y. Jiang, M. Xia, B. Xue, Y. Li, Interface actions between $\mathrm{TiO}_{2}$ and porous diatomite on the structure and photocatalytic activity of $\mathrm{TiO}_{2}$-diatomite, Appl. Surf. Sci., 303 (2014), 290-296
${ }^{25}$ F. Zhang, Y. Pi, J. Cui, Y. Yang, X. Zhang, N. Guan, Unexpected Selective Photocatalytic Reduction of Nitrite to Nitrogen on SilverDoped Titanium Dioxide, J. Phys. Chem. C, 111 (2007), 3756-3761 ${ }^{26}$ S. M. Mukhopadhyay, S. H. Garofalini, Surface studies of $\mathrm{TiO}_{2}-\mathrm{SiO}_{2}$ glasses by X-Ray photoele ctron-spectroscopy, J. Non-Cryst. Solids, 126 (1990), 202-208

${ }^{27} \mathrm{H}$. Gerischer, A. Heller, The role of oxygen in photooxidation of organic-molecules on semiconductor particles, J. Phys. Chem., 95 (1991), 5261-5267

${ }^{28}$ N. Sobana, M. Muruganadham, M. Swaminathan, Nano-Ag particles doped $\mathrm{TiO}_{2}$ for efficient photodegradation of Direct azo dyes, J. Mol. Cataly. A, Chem., 258 (2006), 124-132

${ }^{29}$ A. Takai, P. V. Kamat, Capture, Store, and Discharge. Shuttling Photogenerated Electrons across $\mathrm{TiO}_{2}$-Silver Interface, ACS Nano, 5 (2011), 7369-7376 